\title{
Motivation and Physical Self-Concept in Physical Education: Differences by Gender
}

\author{
Juan Antonio Moreno-Murcia ${ }^{*}, 1$, Elisa Huéscar Hernández ${ }^{1}$, Raúl Reina Vaillo ${ }^{1}$ and \\ Alvaro Sicilia Camacho
}

${ }^{1}$ University Miguel Hernández of Elche, Spain

${ }^{2}$ University of Almería, Spain

\begin{abstract}
This paper examines the relationship between dispositional goal orientations, the perception of different motivational climates and physical self-concept in physical education classes. An additional purpose was to examine the nature of these relationships among boys and girls. Eight hundred and eighty-four students from a large Spanish metropolitan school district were participants in this study and completed questionnaires assessing the above mentioned variables. Results revealed that sport competence and physical condition were the domains of physical self-concept that had a greater connection with goal orientations and motivational climates. Gender differences were also identified for all variables except for task orientation. In addition, the task-involving motivational climate was the main predictor in the sport competence and physical condition subscales in the case of the girls, while ego and task orientation were, respectively, the strongest predictors for the same physical self-concept subscales in the case of the boys. In order to provide more inclusive teaching, especially for students with low self-concept, this study suggests the need to create classroom participation that favours task-involving motivational environments.
\end{abstract}

Keywords: Physical self-concept, gender, goal orientation, motivational climate, physical education, adolescence.

\section{INTRODUCTION}

Research has highlighted that adolescence is a development phase characterised by a high number of physical and psychological changes [1,2]. Physical selfconcept is considered to be a good indicator of the subject's mental and social adjustment in this stage [3]. The subject's motivation can direct and regulate his perceptions and behaviour and, in this respect, it is a key factor in facilitating the students' experiences of achievement [4]. Research has shown that there is a decrease in the students' motivation to take part in physical education activities $[5,6]$ and a decrease in the level of perceived competence [7] as they progress through the school and perceive more academic demands. Given the decrease in the level of physical self-perception and motivation that occurs in the first years of adolescence, it is important to understand the motivational process students are wrapped up in at these ages and their effects on their physical self-perceptions. The achievement goal theory framework [8-10] was used in this study to understand how a student's goal orientations and the climate created by the teacher to enhance motivation might be associated with physical self-concept in adolescent boys and girls.

Self-concept and self-esteem are clearly linked with motivation [11]. In fact, the perception of incompetence and low physical self-perception could lead towards a lack of motivation $[12,13]$. Therefore, the perception one has of

*Address correspondence to this author at the Universidad Miguel Hernández de Elche, Centro de Investigación del Deporte, Avenida de la Universidad, s/n., 03202 Elche, Alicante, Spain; Tel: +34 9652224 41;

E-mail: j.moreno@umh.es oneself is another determining factor of achievement situations. Research has suggested that subjects who perceive themselves as having a high level of competence in a given domain (cognitive, social or physical) are more motivated intrinsically to continue to be committed to the activity and they are more likely to show more effort [14$16]$.

Specifically, research into the physical domain shows evidence to support a relation between perceived competence and motivational processes [17]. Students with a high perception of competence are more likely to select challenging tasks, have fun during the learning process, show more self-esteem, use internal criteria to judge success, use more effort for mastery skills and be more persistent when faced with a difficulty [4]. The theoretical framework of the goal theory has indicated that dispositional goal orientation is related to the way in which individuals construct their level of competence in achievement situations [18]. A subject with task goal orientation tends to focus on tasks, solving problems, doing better than last time and personal improvement. In contrast, an ego-oriented subject tends to display more ability in front of the others at the same time as tending to avoid demonstrating low ability. Therefore, ego and task-oriented people are likely to construct their physical self-perception on the basis of different criteria. However, the perception a student has of himself seems to have a mediating effect on goal orientations in general. For example, Goudas et al. [19] observed that it was more likely for the feeling of competence to be associated with external criteria and the process of comparing oneself with others. 
On the other hand, research has suggested that the perceived motivational climate has an influence on the goals that individuals adopt, as well as on their perceptions, attitudes, behaviour and future commitment to the activities $[8,9,20,21]$. The influence of a positive environment provides an important source of information with which the students can feel better and perceive more competence. In this respect, research in both the physical education and sport context has given detailed a connection between the perception of a task-involving environment and higher levels of self-esteem and physical wellbeing [21] and, in contrast, the perception of an ego-involving climate has been described as a negative predictor of self-esteem [22]. In this regard, López-Valle et al. [22] have showed that a task involvement climate and ego involvement climate were respectively associated with positive and negative selfdetermined motivation, while the latter was positively associated with self-esteem. Finally, self-determined motivation acted as a mediator in the relationship between perceived motivational climate and self-esteem.

From the achievement goals perspective, it is assumed that cognitive, affective and adaptive behavioural patterns correspond to task orientation and a perceived task-involving climate [23] while maladjusted patterns correspond to ego orientation and a perceived ego-involving environment [24] Nevertheless, it has been indicated that these behavioural patterns can be affected by the perception the subject has of himself. Therefore, ego orientation and a perceived egoinvolving climate may lead to a high achievement motivation in those subjects that perceive themselves as having high levels of self-esteem and physical competence $[18,25]$. In this way, some high levels of self-esteem and perceived physical competence would cushion the negative effects of ego orientation and an ego-involving environment on the subjects' mental state [21]. There is also evidence of contributions aimed at encouraging a task-oriented climate and which allows students more autonomy producing more achievement motivation regardless of the perception that the students have of themselves [18].

Therefore, the objective of this study is to examine the relationships between the factors considered for the physical self-concept and achievement motivation in the context of physical education in Spanish schools. The secondary purpose of this study was to examine more closely the contribution of gender influences on achievement motivation and physical self-concept.

It was hypothesised that a positive connection would be found between the perception of a task-involving climate, both goal orientations and physical self-concept. Conversely, a negative association would be found between the perception of an ego-involving climate and physical selfconcept. Gender differences were expected and, in line with previous research [26], it was anticipated that boys would perceive greater ego orientation, perception of an egoinvolving motivational climate and higher levels of physical self-concept than girls.

On the other hand, it was predicted that goal orientations and the perception of a task-involving motivational climate would be linked positively to physical self-concept, while the perception of an ego-involving climate would be linked negatively to physical self-concept. Finally, gender differences were also expected and it was considered that ego and task orientations would be more positively linked to physical self-concept for boys while a task-involving motivational climate would be linked to girls.

\section{METHOD}

\section{Participants and Procedure}

Our study sample consisted of 984 students $(M$ age $=$ $14.8, S D=0.91)$. There were 499 boys and 485 girls, all members of physical education classes in schools in a large Spanish city. All subjects volunteered to participate in the study.

Permission to conduct this research was received from head teachers. The pupils were told the purpose of the research, their rights as study participants and asked to sign a consent form. The instruments for measuring the different variables were administered in a classroom to the chosen subjects when the teacher was not present. The measures were given to all students in the same order. Each participant took 15-20 minutes to complete the questionnaires and responses to the instrument were kept anonymous. The participants were told to ask for help if confused concerning either instructions or the clarity of particular items. No problems were encountered in completing either of the inventories or understanding the nature of the questions.

\section{Measures}

Perception of Success Questionnaire (POSQ). To measure students' dispositional goal orientation in physical education classes, the Spanish version [27-29]. This questionnaire has 12 items, of which six measure task orientation (e.g. "In physical education classes, I feel successful when I reach a goal") and six measure ego orientation (e.g. "In physical education classes, I feel successful when I win"). The replies are rated on a Likerttype scale, in which each item has a response range from 1 to 100 (anchors: $0=$ strongly disagree and $10=$ strongly agree). The Spanish version of this questionnaire showed a factor distribution and internal consistency coefficients similar to those obtained for American athletes and physical education students [28, 29]. Likewise, the inventory for this study showed adequate internal consistency for each subscale, with Cronbach alpha coefficients from .93 for the ego orientation subscale and .87 for the task orientation subscale.

Perception of Motivational Climate in Sport Questionnaire-2 (PMCSQ-2). To measure students' perception of a motivational climate in physical education classes, the version translated into Spanish by Balaguer et al. [30] of the Perception of Motivational Climate in Sport Questionnaire-2 [31] was adapted. The Spanish version of this questionnaire has two higher-order dimensions, which measure the perception of a task-involving motivational climate and the perception of an ego-involving motivational climate. In the Spanish version, the task-involving climate factor is composed of 11 items. Examples of the items included: "In physical education classes, students feel good when they try their best" and "In physical education classes, students help each other learn". The ego-involving climate factor includes 13 items (e.g. "In physical education classes, the teacher has his/her favourites"). The replies to the questionnaire were indicated on a Likert-type scale with a 
response range of 0 to $10(0=$ strongly disagree to $10=$ strongly agree). Studies carried out with Spanish athletes have shown a factor distribution and internal consistency coefficients similar to those found in athletes and students in other countries [28, 30]. This inventory has indicated adequate internal consistency for each subscale, with Cronbach alpha coefficients from .71 for the ego-involving motivational climate subscale and .74 for the task-involving motivational climate subscale.

Physical Self-Perception Profile (PSPP). The Spanish adaptation [32] of the Physical Self-Perception Profile [33, 34] was used. The original instrument is composed of 30 items and five factors. The Spanish version [32] was called Physical-Self Questionnaire (PSQ) and showed five subscales too, but with a different item factor distribution: sport competence, body image, physical condition, physical strength and self-confidence. The alphas were between .85 and .62. To date, the PSPP has been a good instrument to measure physical self-concept [35-37].

In the Spanish academic context, all assessments of pupils' academic performance are ranged between 0 and 10 . In order to make it easier for the students to reply in a more usual way, all the responses were indicated on a 10-point Likert scale anchored to strongly disagree (0) and strongly agree (10).

\section{RESULTS}

In this section, firstly, we show the descriptive statistics, the estimated reliability coefficients and the correlations of the variables analysed. Secondly, a univariate analysis of variance of gender is presented. Finally, in order to analyse the power of prediction of achievement goals and the perception of a motivational climate in the different factors of physical self-concept, hierarchical regression analysis was used.

\section{Descriptive Statistics, Reliability and Correlations}

The descriptive statistics of the instruments used in the research, the estimated reliability coefficients and the correlations between the variables analysed in the study are shown in Table $\mathbf{1}$.
The means of the factors show that our physical education students have moderate ego orientation and high task orientation. They also perceive a low ego-involving climate and a moderate task-involving climate. Moreover, the results for the students are moderate for each of the five subscales of physical self-concept.

Regarding reliability coefficients, the values in all the scales exceed .70 and we can consider that the reliability of the instruments is adequate $[38,39]$.

With regard to the correlations of the variables, we can observe positive and significant connections between the perception of ego orientation and an ego-involving motivational climate and between the perception of task orientation and a task-involving motivational climate. Similarly, there are negative and significant correlations between the perception of task orientation and an egoinvolving motivational climate, but not between the perception of ego orientation and a task-involving motivational climate.

On the other hand, the two goal orientations (ego and task) were positively correlated with each of the five factors considered for physical self-concept. Similarly, the perception of a task-involving motivational climate was associated positively with the same factors except body attractiveness. Nevertheless, the physical self-concept subscales that obtained higher correlation values with goal orientations and the perception of a task-involving motivational climate were sport competence and physical condition.

\section{ANOVA by Gender}

To examine the hypothesis that gender would be associated with goal orientations, motivational climate and physical self-concept, a one-way ANOVA was conducted with gender as the independent variable and the latter group as dependent variables (see Table 2). Follow-up univariate F-test indicated that ego orientation $(F=71.36, p<.001)$, an ego-involving motivational climate $(F=34.00, p<.001)$ and a task-involving motivational climate $(F=5.77, p<.05)$ contributed significantly to group differentiation. Boys endorsed ego orientation $(M=59.66)$, an ego-involving

Table 1. Descriptive Statistics, Alpha Coefficients and Correlations by All Factors

\begin{tabular}{|c|c|c|c|c|c|c|c|c|c|c|c|c|}
\hline 1. Ego orientation & 5.20 & 2.98 & .92 & - & $.39 * *$ & $.21 * *$ & .04 & $.12 * *$ & $.31 * *$ & $.30^{* *}$ & $.21 * *$ & $.13 * *$ \\
\hline 3. Ego-involving motivational climate & 3.25 & 1.45 & .77 & - & - & - & $-.27 * *$ & .00 & .01 & .05 & .04 & -.01 \\
\hline 4. Task-involving motivational climate & 6.11 & 1.50 & .73 & - & - & - & - & .04 & $.23 * *$ & $.27^{* *}$ & $.09^{* *}$ & $.16^{* *}$ \\
\hline 6. Sport competence & 5.40 & 2.12 & .77 & - & - & - & - & - & - & $.75^{* *}$ & $.62 * *$ & $.55 * *$ \\
\hline 7. Physical condition & 5.64 & 2.04 & .74 & - & - & - & - & - & - & - & $.56^{* *}$ & $.66 * *$ \\
\hline 8. Physical strength & 5.24 & 1.96 & .74 & - & - & - & - & - & - & - & - & $.47 * *$ \\
\hline 9. Self-confidence & 5.96 & 1.94 & .72 & - & - & - & - & - & - & - & - & - \\
\hline
\end{tabular}


motivational climate $(M=3.51)$ and a task-involving motivational climate $(M=6.22)$ more strongly than girls $(M$ $=4.41 ; M=2.93 ; M=5.99)$. In accordance with the subscales considered to measure physical self-concept, univariate F-test indicated significant gender differences in body attractiveness $(F=38.89, p<.001)$, sport competence $(F=171.68, p<001)$, physical condition $(F=173.08, p<$ $001)$, physical strength $(F=99.06, p<001)$ and selfconfidence $(F=65.68, p<001)$. As shown in Table 2 , the group of boys obtained higher mean values than the group of girls in all the physical self-concept factors. The most differences between boys and girls were obtained in the sport competence and physical condition factors.

\section{Hierarchical Multiple Regression and Gender}

Two multiple regression analyses were conducted to examine how orientations and motivational climate affect each of the physical self-concept factors (see Tables $\mathbf{3}$ and 4). Firstly, the scorings for each subscale of self-concept were hierarchically regressed on the following variables: a)

Table 2. Analysis of Variance by Gender

\begin{tabular}{|c|c|c|c|c|c|c|}
\hline Pupil's Gender & Boys & $S D$ & Girls & $S D$ & $\boldsymbol{F}$ & $p$ \\
\hline Ego orientation & 5.96 & 2.93 & 4.41 & 2.82 & 71.36 & .000 \\
\hline Task orientation & 7.84 & 2.04 & 7.71 & 2.11 & 1.05 & .305 \\
\hline Ego-involving motivational climate & 3.51 & 1.53 & 2.98 & 1.32 & 34.00 & .000 \\
\hline Task-involving motivational climate & 6.22 & 1.50 & 5.99 & 1.50 & 5.77 & .016 \\
\hline Body attractiveness & 5.95 & 1.75 & 5.20 & 2.04 & 38.89 & .000 \\
\hline Sport competence & 6.20 & 1.99 & 4.57 & 1.92 & 171.68 & .000 \\
\hline Physical condition & 6.42 & 1.96 & 4.84 & 1.80 & 173.08 & .000 \\
\hline Physical strength & 5.82 & 1.96 & 4.63 & 1.77 & 99.06 & .000 \\
\hline Self-confidence & 6.44 & 1.72 & 5.47 & 2.02 & 65.68 & .000 \\
\hline
\end{tabular}

Table 3. Summary of the Multiple Regression Analysis for Variables Predicting Self-Concept in Physical Education Classes

\begin{tabular}{|c|c|c|c|c|}
\hline Factors & $B$ & $S E B$ & $\beta$ & $\Delta R^{2}$ \\
\hline Body attractiveness & 48.05 & 3.76 & & $.01 * *$ \\
\hline Ego orientation & .07 & .02 & $.12 *$ & \\
\hline Task orientation & .01 & .03 & .02 & \\
\hline Ego-involving motivational climate & -.01 & .04 & -.01 & \\
\hline Task-involving motivational climate & .04 & .04 & .03 & \\
\hline Ego orientation & .18 & .02 & $.26^{* *}$ & \\
\hline Task orientation & .10 & .03 & $.09^{*}$ & \\
\hline Ego-involving motivational climate & .03 & .04 & .02 & \\
\hline Task-involving motivational climate & .27 & .04 & $.19 * *$ & \\
\hline Physical condition & 9.87 & 3.60 & & $.19 *$ \\
\hline Task-involving motivational climate & .32 & .04 & $.23 * *$ & \\
\hline Physical strength & 31.88 & 3.74 & & $.05 * *$ \\
\hline Ego orientation & .10 & .02 & $.15^{* *}$ & \\
\hline Task orientation & .10 & .03 & $.11 *$ & \\
\hline Ego-involving motivational climate & .06 & .04 & .04 & \\
\hline Task-involving motivational climate & .08 & .04 & .06 & \\
\hline Self-confidence & 38.16 & 3.71 & & $.04 * *$ \\
\hline Ego orientation & .05 & .02 & $.08^{*}$ & \\
\hline Task orientation & .10 & .03 & $.10^{*}$ & \\
\hline Ego-involving motivational climate & .02 & .04 & .01 & \\
\hline
\end{tabular}


Tabla 4. Summary of the Multiple Regression Analysis for Variables Predicting Self-Concept in Physical Education Classes by Gender

\begin{tabular}{|c|c|c|c|c|c|c|c|c|}
\hline \multirow{2}{*}{ Factors } & \multicolumn{4}{|c|}{ Boys } & \multicolumn{4}{|c|}{ Girls } \\
\hline & $B$ & $S E B$ & $\beta$ & $\Delta R^{2}$ & $B$ & $S E B$ & $\beta$ & $\Delta R^{2}$ \\
\hline Body attractiveness & 48.82 & 4.75 & & $.03 * *$ & 53.80 & 5.98 & & $.00^{* *}$ \\
\hline Ego orientation & .04 & .03 & .07 & & .04 & .03 & .06 & \\
\hline Task orientation & .11 & .04 & $.13 *$ & & -.04 & .05 & -.04 & \\
\hline Ego-involving motivational climate & -.06 & .05 & -.05 & & -.03 & .07 & -.02 & \\
\hline Sport competence & 31.89 & 5.05 & & $.15^{* *}$ & 17.64 & 5.34 & & $.09 *$ \\
\hline Ego orientation & .16 & .03 & $.24 * *$ & & .08 & .03 & $.12 *$ & \\
\hline Task orientation & .17 & .04 & $.18^{* *}$ & & .07 & .04 & .08 & \\
\hline Ego-involving motivational climate & -.07 & .05 & -.05 & & .00 & .06 & .00 & \\
\hline Task orientation & .29 & .04 & $.30 * *$ & & .14 & .04 & $.17^{*}$ & \\
\hline Ego-involving motivational climate & .02 & .05 & .01 & & .16 & .06 & $.11 *$ & \\
\hline Task-involving motivational climate & .22 & .05 & $.17^{* *}$ & & .30 & .05 & $.25 * *$ & \\
\hline Physical strength & 35.67 & 5.22 & & $.07^{* *}$ & 38.07 & 5.17 & & $.00 * *$ \\
\hline Ego orientation & .07 & .03 & $.10^{*}$ & & .04 & .03 & .06 & \\
\hline Task orientation & .18 & .05 & $.19^{* *}$ & & .07 & .04 & .09 & \\
\hline Ego-involving motivational climate & -.03 & .06 & -.02 & & .05 & .06 & .03 & \\
\hline Task-involving motivational climate & .083 & .06 & .06 & & -.01 & .06 & -.01 & \\
\hline
\end{tabular}

task and ego orientations and b) perceived task-involving and ego-involving climate. Secondly, a multivariate multiple-regression analysis was conducted to examine the strength of the relationship between the sets of goal orientations and motivational climate variables for both boys and girls.

As shown in Table 3, although goal orientations and motivational climates predict a certain percentage of the variance for each one of the five physical self-concept factors, corrected $\mathrm{R}^{2}$ only obtain values the same as or greater than 15 in the case of the sport competence and physical condition factors. Specifically, positive task and ego orientation and positive perceptions of a task-involving climate predicted $15 \%$ of the variance for the perception of sport competence. However, the beta value ego orientation and perceptions... to read: However, the beta values suggest that the effect of ego orientation and perception of a taskinvolving motivational climate on the perception of sport competence were higher than ego task orientation. In the case of the perception of physical condition, both task and ego orientation and task and ego-involving motivational climate were positive predictors explaining $19 \%$ of the variance of this variable. Nevertheless, the beta value shows that the task-involving motivational climate was the strongest predictor of the physical condition variable.

Taking a hierarchical multiple regression for the boys and girls we can see in Table 4 that there was a gender difference with regard to the variance. Corrected $\mathrm{R}^{2}$ values in the five factors were higher in the group of boys than in the group of girls. Within each group, the sport competence and physical condition variables were the ones that obtained higher values in $\mathrm{R}^{2}$. Specifically, ego orientations and taskinvolving motivational climates predicted $9 \%$ of the variance for the perception of sport competence in girls, while goal orientations and task-involving motivational climates predicted $15 \%$ for the same variable in boys. On the other hand, task orientations and motivational climates predicted $11 \%$ of the variance for the perception of physical condition in girls, while goal orientations and task-involving motivational climates predicted $22 \%$ for the same variable in 
boys. Considering the Beta values, we can observe in Table 4 that task-involving motivational climates particularly affect the perception of sport competence and physical condition in girls, while for boys the strongest predictor was ego orientation for the first variable and task orientation for the second.

\section{DISCUSSION}

The first purpose of this study was to research the relationships between physical self-concept and achievement motivation in physical education classes. Our results have shown that dispositional goal orientations were associated with the perception of the two motivational climates. There were positive and significant connections between the perception of an ego orientation and an ego-involving motivational climate and between the perception of task orientation and a task-involving motivational climate. There were also negative and significant correlations between the perception of a task orientation and an ego-involving motivational climate. Data from this study was consistent with previous studies, which have pointed out the associations between dispositional achievement goals and the perception of motivational climates within educational contexts [28, 40]. However, negative and significant correlations between the perception of an ego orientation and a task-involving motivational climate were not found.

This study has also shown that both dispositional goal orientations and the perception of the two motivational climates were related to the physical self-concept. Even when the results show that a high task orientation is associated with adaptive patterns [4, 21, 41], the relation patterns between dispositional goals and physical selfconcept also suggest that the meanings that the students attribute to achievement could be an important determining factor of the perception they have of themselves. Specifically, this study reveals that both task orientation and ego orientation were associated positively with the different physical self-concept subscales. In addition, in line with prior studies carried out with SPSS $[32,37]$ the strongest association between goal orientations and physical selfconcept were found in the sport competence and physical condition subscales, which, according to research, are the ones that best predict physical self-concept.

These results seem to be in line with the hypotheses defended by achievement goal theory, given that task or ego orientation are connected with the way in which the subject perceives himself and constructs his level of competence in situations of achievement [18]. A task-involved student is more likely to perceive himself as physically competent as long as he tends to focus on tasks, tries to solve problems and tries to do better instead of trying to demonstrate more ability than the others. In contrast, an ego-oriented student is more likely to have a high physical self-concept when he manages to demonstrate more ability in front of the others. Given that success is based on normative comparison, personal improvement will not be enough to satisfy the aim of demonstrating more ability [42]. In this respect, physical self-concept would be constructed from internal and external references, but with the subject attaching more importance to some than to others, depending on his dispositional goal orientation. Nevertheless, these results are inconsistent with other research. For example, Goudas et al. [19] found that ego orientation was the strongest predictor of perceived competence in physical education classes. More work is required to clarify the effects of goal orientations on the different physical self-concept factors.

On the other hand, observing the results that relate motivational climates and physical self-concept, we have found that the students participating in this study were more likely to perceive higher levels of sport competence, physical condition and self confidence when they reported that the teachers focused on students' learning rather than on their abilities. However, there was no correlation between the perception of an ego-involving motivational climate and some of the physical self-concept subscales. This means that, contrary to expectations, our data indicate that emphasising performance in physical education classes would not have a negative effect on the students' physical self-concept. In contrast, a high physical self-concept is more likely when there is an emphasis on the improvement of children's abilities.

These results are partially in line with achievement perspectives, since students are more likely to respond with an adaptive behaviour when the meaning of achievement emphasised in physical education classes is based on personal improvement and effort level than on performance and ability $[8,9,18]$. The fact that there has not been a negative and significant association between the perception of an ego-involving motivational climate and any of the physical self-concept subscales could be explained by the possibility of a perceived ego-involving environment displaying a high achievement motivation in those students that perceive themselves as having high levels of competence and physical self-concept $[18,22]$. A high perceived competence would cushion the negative effects of an ego-involving environment on the subjects' mental state. In this way, the students' physical perception would curb the effect of an ego goal emphasis on achievement-related patterns [18]. Moreover, our results indicated that the perception of an ego-involving motivational climate was a positive predictor in some of the PSPP subscales (i.e. physical condition). Nevertheless, these results seem inconsistent with other research that has shown the perception of an ego-involving motivational climate as a negative predictor of self-esteem and physical wellbeing [43] and a positive predictor of emotional and physical exhaustion [21]. More research is necessary to identify the extent to which the perception of ego-oriented environments affect the way in which students perceive themselves in the physical domain.

The second purpose of this study was to examine gender influences to explain variability in students' goal orientations, motivational climates and physical self-concept. The boys show higher mean values than the girls in all the variables considered and there are significant differences in all the values except in task orientation. In this respect, we can say that, on the one hand, our results partially coincide with research carried out from a goal achievement perspective [44], given that in this research it is stated that girls generally endorse task orientation and a task-involving motivational climate more strongly than boys. On the other hand, our results are in line with a large number of studies 
that have analysed physical self-concept using SPSS [32]. This research has pointed out that boys usually score higher mean values than girls in all the SPSS subscales, with the most marked differences being found in the sport competence and physical condition subscales. Nevertheless, there are a few studies [45] that do not indicate any significant gender differences for the SPSS subscales.

From the point of view of motivational psychology, and more specifically from the goal perspective, it is difficult to find a clear explanation of gender differences. Nevertheless, we could suggest in this case the influence of other social factors. We must not forget that women have been stereotyped as biologically and physically inferior to men. As has been widely confirmed, gender stereotypes penetrate into the dynamics of physical education classes and pressurise children to express and demonstrate certain images and behaviour that satisfy the expectations of the group and of society in general [46]. In fact, as social psychology has proved, we must not forget that individual perceptions are influenced by stereotypes upheld by the social group one belongs to [47]. As a result, the image and perception students have would be affected by gender stereotypes, especially in those domains involving a display of features clearly stereotyped as masculine or feminine. As evidenced, these stereotypes usually limit the participation of girls in physical and sport activities [48].

In accordance with the gender regression analysis, the results indicate that goal orientations and motivational climates predicted a higher percentage of the variance in boys than in girls for each of the different physical selfconcept subscales. Nevertheless, sport competence and physical condition were the subscales where a higher percentage of explained variance was found, with differences on the predictor factors of these variables. Specifically, the perception of a task-involving motivational climate was the strongest predictor of sport competence and physical condition in the case of the girls, while ego and task orientation were, respectively, the strongest predictors for these same subscales.

The Goal Achievement Theory may be of help when explaining the physical self-concept differences between girls and boys in physical education classes. The results indicated that boys perceived higher physical self-concept values than girls and this perception was associated with their goal orientation and the different way in which they perceived the class environment. This finding is coherent with studies that have demonstrated how gender determines children's perception within physical education classes and how it affects task engagement. Specifically, research that has examined the treatment of children of different genders has demonstrated that girls receive less positive feedback and do not have the same chances to participate as boys [49]. Teachers generally pay more attention to boys than girls and, as research shows, it is likely that children are aware of this unequal treatment and that it affects their perception and behaviour [50]. In particular, given that physical self-concept and especially sport competence and physical condition scales refer to beliefs that the subjects have on how able they are in different achievement domains, accuracy in the perception of the physical domain has been recognised to be as important as the perception of the level of sport competence or physical condition that one thinks one has [7]. Girls are more likely to perceive that they have less physical competence in physical education classes [51] than they actually have. In other words they underestimate their physical competence. The expectations created by teachers, but also group pressures, could affect the image that boys and girls have of themselves. In the latter case, the construction of an athletic image for a girl could be seen as inappropriate in certain situations $[48,52]$. Given the social role girls assume, rather than show interest in a task goal orientation, they could be shying away from showing an ego goal orientation. As Weiss and Horn [53] demonstrated, subjects that underestimate their physical competence are usually not as motivated by challenges and are more anxious in competition compared with those than overestimate their physical competence or assess it correctly.

There is evidence that contributions aimed at encouraging a task-involving motivational climate that allows students more autonomy will lead to more achievement motivation, especially for those groups of students that achieve less or are more at risk of failing at school $[8,9]$. In this respect, Fox [54] found that the effects of a physical exercise programme seemed to be particularly obvious in children that had low self-esteem initially. Along these lines, girls could be potential candidates for the design of exercise programmes that promote self-esteem [22, 32]. Therefore, the results of recent studies suggest that in order to improve students' physical self-concept, teachers should encourage task-oriented climates instead of atmospheres that encourage performance. Although an ego-motivational climate could have positive effects on those students that started off with high levels of competence and physical selfperception, the truth is that these environments could limit the opportunities of the other children to learn and develop physical self-perceptions. A task-involving motivational climate is more likely to maintain or increase levels of selfesteem, especially in girls and in those that started off with low physical self-concept levels, because competence is based on self-reference and success is defined in terms of mastery, effort and doing better than last time. From that point of view, this can be achieved by considering the six dimensions (tasks, authority, recognition, grouping, evaluation and time) proposed by Epstein (1988a, b, 1989). The instructional strategies that include the TARGET structure have been described as effective in producing a positive change in the perception of physical competence $[8$, 9].

\section{ACKNOWLEDGEMENT}

Declared none.

\section{CONFLICT OF INTEREST}

\author{
Declared none.
}

\section{REFERENCES}

[1] Ganiban JM, Saudino KJ, Ulbricht J, Neiderhiser JM, Reiss D. Stability and change in temperament during adolescence. J Pers Soc Psychol 2008; 95(1): 222-36.

[2] Yurgelun TD. Emotional and cognitive changes during adolescence. Curr Opin Neurobiol 2007; 17(2): 251-7.

[3] Ybrandt $H$. The relation between self-concept and social functioning in adolescence. J Adolesc 2008; 31(1): 1-16. 
[4] Roberts GC, Treasure DC, Conroy DE. Understanding the dynamics of motivation in sport and physical activity: An achievement goal interpretation. In: Tenenbaum G, Ecklund R. Eds. Handbook of sport psychology. Hoboken, NJ: John Wiley \& Sons Inc 2007; pp. 3-30.

[5] Caspersen CJ, Pereira MA, Curran KM. Changes in physical activity patterns in the United States, by sex and cross-sectional age. Med Sci Sports Exerc 2000; 32: 1601-9.

[6] Kimm S, Glynn NW, Obarzanik E, et al. Relation between changes in physical activity and body-mass index during adolescence: a multicentre longitudinal study. Lancet 2005; 366: 301-7.

[7] Weiss MR, Amorose AJ. Children's self-perceptions in the physical domain: between- and within- age variability in level, accuracy, and sources of perceived competence. J Sport Exerc Psychol 2005; 27: 226-44.

[8] Ames C. Achievement goals, motivational climate and motivational processes. In: Roberts Ed., Motivation in Sport and Exercise. Champaign, IL: Human Kinetics 1992; pp. 161-76.

[9] Ames C. Classrooms, goals, structures and student motivation. J Educ Psychol 1992b; 84: 261-71.

[10] Kaplan A, Maehr ML. The contributions and prospects of goal orientation theory. Educ Psychol Rev 2007; 19: 141-84.

[11] Ommundsen Y, Haugen R, Lund T. Academic self-concept, implicit theories of ability, and self-regulation strategies. Scand J Educ Res 2005; 49(5): 461-4.

[12] Moreno JA, Parra N, González-Cutre D. Influencia del apoyo a la autonomía, las metas sociales y la relación con los demás sobre la desmotivación en educación física. Psicothema 2008; 20: 636-41.

[13] Ryan RM, Deci EL. Intrinsic and extrinsic motivation in exercise and sport. In: Hagger MS, Chatzisarantis NL, Eds. Intrinsic motivation and self-determination in exercise and sport. Champaingn, IL: Human Kinetics 2007; pp. 1-19.

[14] Cecchini JA, González C, Méndez A, Fernández-Río J, Contreras $\mathrm{O}$, Romero S. Metas sociales y de logro, persistencia-esfuerzo e intenciones de práctica deportiva en el alumnado de Educación Física. Psicothema 2008; 20: 260-5.

[15] Hodge K, Allen JB, Smellie L. Motivation in masters sport: achievement and social goals. Psychol Sport Exerc 2008; 9: 15776.

[16] Moreno JA, González-Cutre D, Sicilia A. Metas sociales en las clases de educación física. Análisis y Modificación de Conducta 2007; 33: 351-68.

[17] Stuntz CP, Weiss MR. Achievement goal orientations and motivational outcomes in youth sport: the role of social orientations. Psychol Sport Exerc 2009; 10: 255-62.

[18] Nicholls JG. The competitive ethos and democratic education. Cambridge, MA: Harvard University Press 1989.

[19] Goudas M, Biddle S, Fox K. Perceived locus of causality, goal orientations and perceived competence in school in school physical education lessons. Br J Educ Psychol 1994; 64: 453-63.

[20] Papaioannou AG, Tsigilis N, Kosmidou E, Milosis D. Measuring perceived motivational climate in physical education. J Teach Phys Educ 2007; 26: 236-59.

[21] Reinboth M, Duda JL. Perceived motivational climate, need satisfaction and indices of well-being in team sports: a longitudinal perspective. Psychol Sport Exerc 2006; 7: 269-86.

[22] López-Walle J, Balaguer I, Castillo I, Tristán J. Clima motivacional percibido, motivación autodeterminada y autoestima en jóvenes deportistas mexicanos Revista de Psicología del Deporte 2011; 20(1): 209-22.

[23] Quested E, Duda JL. Perceptions of the motivational climate, need satisfaction, and indices of well- and ill-Being among hip hop dancers. J Dance Med Sci 2009; 13: 10-9.

[24] Newton ML, Duda JL, Yin Z. Examination of the psychometric properties of the perceived motivational climate in sport questionnaire-2 in a simple of female athletes. J Sport Sci 2000; 18 : 275-90.

[25] Duda JL, Balaguer I. The Coach-created motivational climate. In: Lavalee D, Jowett S Eds. Social Psychol Sport. Champaign, IL: Human Kinetics 2007; pp. 117-38.

[26] Kavussanu M, Roberts GC. Moral functioning in sport: an achievement goal perspective. J Sport Exerc Psychol 2001; 23: 37 54.

[27] Cervelló E, Escartí, A, Balagué G. Relaciones entre la orientación de metas disposicional y la satisfacción con los resultados deportivos, las creencias sobre las causas de éxito en deporte y la diversión con la práctica deportiva. Revista de Psicología del Deporte 1999; 8: 7-19.

[28] Cervelló E, Santos-Rosa F. Motivación en las clases de educación física: un estudio de la perspectiva de las metas de logro en el contexto educativo. Revista de Psicología del Deporte 2000; 9: 5170 .

[29] Cervelló E, Santos-Rosa, F. Motivation in sport: an achievement goal perspective in young Spanish recreational athletes. Percept Mot Skills 2001; 92: 527-34.

[30] Balaguer I, Guivernau M, Duda JL, Crespo M. Análisis de la validez de constructo y de la validez predictiva del cuestionario de clima motivacional percibido en el deporte (PMCSQ-2) con tenistas españoles de competición. Revista de Psicología del Deporte 1997; 11: 41-57.

[31] Newton M, Duda JL. Elite adolescent athletes' achievement goals and beliefs concerning success in tennis. J Sport Exerc Psychol 1993; 15: 437-48.

[32] Moreno JA, Cervelló E. Physical self-perception in spanish adolescents: gender and involvement in physical activity effects. J Hum Mov Stud 2005; 48: 291-311.

[33] Fox KR. The physical self-perception manual. Dekalb, IL: Office for Health Promotion, Northern Illinois University 1990.

[34] Fox KR, Corbin CB. The Physical Self-Perception Profile: Development and preliminary validation. J Sport Exerc Psychol 1989; 11: 408-30.

[35] Asçi F. The construct validity of two physical self-concept measures: An example from Turkey. Psychol Sport Exerc 2005; 20: 1-11.

[36] Asçi F, Eklund RC, Whitehead JR, Kirazci S, Koca, C. Use of the CY-PSPP in other cultures: a preliminary investigation of its factorial validity for Turkish children and youth. Psychol Sport Exerc 2005; 6: 33-50.

[37] Hagger M, Biddle S, Wang, CK. Physical Self-Concept in adolescence: generalizability of a multidimensional, hierarchical model across gender and grade. Educ Psychol Measur 2005; 65(2): 297-322.

[38] Nunnally JC. Psychometric theory. New York: McGraw-Hill 1978.

[39] Nunnally JC, Berstein IH. Psychometric theory. New York: McGraw-Hill 1994.

[40] Smith RE, Smoll FL, Cumming SP. Motivational climate and changes in young athletes' achievement goal orientations. Motiv Emot 2009; 3(2): 173-83.

[41] Ommundsen Y, Kvalo SE. Autonomy-mastery, supportive or performance focused? Different teacher behaviours and pupils' outcomes in physical education. Scand J Educ Res 2007; 51: 385413.

[42] Xiang P, Mcbride R, Guan J. Children's motivation in elementary physical education: A longitudinal study. Res Q Exerc Sport 2004; 75(1): 71-80.

[43] Duda JL, Kim MS. Perceptions of the motivational climate, psychological characteristics, and attitudes toward eating among young female gymnasts. J Sports Exerc Psychol 1997; 19(Suppl): S132.

[44] Moreno JA, Cervelló E, González-Cutre D. Relationships among goal orientations, motivational climate and flow in adolescent athletes: Differences by gender. Span J Psychol 2008; 11(1): 18191.

[45] Welk, GJ, Eklund B. Validation of the children and youth physical self perceptions profile for young children. Psychol Sport Exerc 2005; 6: 51-65.

[46] Shropshire J, Carroll B, Yim S. Primary school children's attitudes to physical education: gender differences. Eur J Phys Educ 1997; 2(1): 23-38.

[47] Meece JL, Glienke BB, Burg S. Gender and motivation. J Sch Psychol 2006; 44: 351-73.

[48] Solmon MA, Lee, AM, Belcher D, Harrison L, Wells L. Beliefs about gender appropriateness, ability and competence in physical activity. J Teach Phys Educ 2003; 22: 261-79.

[49] Lirgg CD. Effects of same-sex versus coeducational physical education on the self-perceptions of middle and high school students. Res Q Exerc Sport 1993; 64(3): 324-34.

[50] Cervelló EM, Jiménez R, Del Villar F, Ramos L, Santos-Rosa FJ. Goal orientations, motivational climate, equality and discipline of Spanish physical education students. Percept Mot Skills 2004; 99: 271-83. 
[51] Moreno JA, Cervelló E, Vera JA, Ruiz, LM. Physical self-concept of Spanish schoolchildren: differences by gender, sport practice levels of sport involvement. J Educ Hum Dev 2007; 1: 1-17.

[52] Li W, Harrison L Jr, Solmon J, Solmon M. College students' implicit theories of ability in sports: race and gender differences. $\mathbf{J}$ Sport Behav 2004; 27(3): 291-304.
[53] Weiss MR, Horn TS. The relationship between children's accuracy estimates of their physical competence and achievement-related behaviors. Res Q Exerc Sport 1990; 61: 250-8.

[54] Fox KR. Self-esteem, self-perceptions and exercise. Int J Sport Psychol 2000; 31: 228-40.

(C) Moreno-Murcia et al.; Licensee Bentham Open.

This is an open access article licensed under the terms of the Creative Commons Attribution Non-Commercial License (http://creativecommons.org/licenses/by-nc/3.0/) which permits unrestricted, non-commercial use, distribution and reproduction in any medium, provided the work is properly cited. 